\title{
The State and Governance: The Main Bottlenecks for Absorbing Massively Increased Aid?
}

\section{Albrecht Stockmayer}

\section{The status of capacity development for governance}

Massively increased aid flows will meet an ongoing reform process in Africa. The process of governance reforms is not new - in fact it can be traced back to the 1980 Lagos Plan of Action. Recently it has been reinvigorated, as it has benefited from the parallel support of the African states and the G8 group since the Kananaskis Summit in 2002. It is characterised by the recognition that African states claim and accept the principal responsibility for their social and political transition and reform processes. This consensus has found its clearest expression in the reform of the African Union and the creation of various mechanisms such as the New Partnership for African Development's (NEPAD) African peer review mechanism (APRM), as well as regional and sub-regional initiatives. These initiatives are in the process of being implemented, and progress is visible in many fora, but it is too early for impacts to be shown at the national level where the Millennium Development Goals (MDGs) are measured. Initiatives are also being better linked to national or regional civil society capacities that are needed to drive these reforms from below.

These initiatives as well as the Cotonou partnership of the European Union permit a more fruitful dialogue among and within African states on governance issues which in turn may help to put governance work on a more sound footing. In parallel, donors are currently pursuing joint and separate activities to strengthen the sustainability and the impact of instruments such as the Poverty
Reduction Strategy Papers (PRSPs), mostly in the areas of public administration and public financial management in general and, more particularly, in supervision, control and auditing. In the policy cluster of safety and security, the first steps for common strategies and action have successfully been taken on the sub-regional level.

The national picture for governance activities is very varied. Similar sector-wide approaches (SWAp) on law and justice in neighbouring countries have had quite different trajectories in recent times (e.g. Uganda, Kenya and Tanzania). Other equally demanding reform processes allowing participation in policy analysis and development (e.g. on budget reforms) have not reached the status of institutional deepening, let alone of sustained application. More fundamental issues of cooperation with countries that show less favourable framework conditions have not yet been tackled with the necessary resolve.

These processes have succeeded in building up some capacity. They have allowed African governments and citizens to have a greater say in the way their countries are involved in international efforts for better governance. Increased aid flows will necessarily lead to substantive changes in incentives and, above all, in relations of power and influence given the concomitant changes in structures and relations that shape the political process.

Budget-financed programmes of the SWAp and PRSP type cover many sectors and levels, and have led to an increasingly complex reform architecture. One case in point is decentralisation, one of the 
reforms that is thought to unleash capacities and to bring policy making closer to civil society.

Decentralisation processes deal primarily with functional and territorial reform issues. But they involve many other areas such as civil service reform as they try to combine "downsizing" and "rightsizing" of national and sub-national organisations. These reform aspects become more urgent as the measure of capacity needed on the local level becomes apparent and the multiple requests to increase jobs at this level have to be addressed.

Another major reform area for decentralisation is the transfer, sharing and generation of revenues. Broadening tax bases for the local level and improving revenue flows through responsible and legitimate government are essential parts of these reforms. They are particularly sensitive to changes in the availability of funds.

Accounting and auditing are reform areas, linked to decentralisation but following its own rationale. In weak policy and management environments, both stress the repressive part of auditing and thus are of little help to newly decentralised organisations groping with new tasks. They have not factored in roles for the private sector or decentralised internal audit institutions in a decentralised environment. Nor can they take into consideration emerging instruments and practice for public administration supervision and control in a decentralised environment.

If decentralisation is to have any effect on poverty reduction, civil society needs to get involved in policy analysis, policy making and in exercising some measure of "social control". There are many very positive experiences in this area, but also many cases where misguided accountability did not improve the quality of public services but disrupted public administration decision making. Moreover, mechanisms of accountability across levels of government and the coordination between internal control and external accountability take a long time to mature.

These reforms are lengthy, costly and involve almost every part of society. They do not, by their nature, lend themselves to an acceleration brought about by outside influence. The reasons are well known. Programmes are in reality a host of different reform processes that are driven by different micro-motives, which depend on different coalitions of actors and involve different resources. Increased fund flows are liable to change the balance of power and relations between reform actors that are driving the process and the direction the reform process takes. The chances that the impact of changed incentives can be managed appear rather slim. On the other hand, the risk that increased fund flows will interfere with emerging democratic processes are all too apparent.

While it may be theoretically easy to increase spending by increasing the number of spending and accounting entities (local governments, autonomous authorities, etc.) using additional funds to produce reform results would require wellestablished systems of commonly accepted rules, buttressed by a common profile of civil servants, for example based on a common induction and public sector training, similar recruitment procedures and career paths.

\section{The time factor}

The Commission for Africa report puts it succinctly in its summary: 'Building capacity needs time and commitment'. But time is a precious commodity, especially for donors, as they pursue their strategies and programmes in rapid succession. The chances that these programmes will tend to supersede each other, regardless of their implementation, are not remote.

The Kananaskis G8 African Action Plan 2002 reads:

NEPAD recognizes that the prime responsibility for Africa's future lies with Africa itself. We will continue to support African efforts to encourage public engagement in the NEPAD and we will continue to consult with our African partners on how we can best assist their own efforts. G8 governments are committed to mobilize and energize global action, marshal resources and expertise, and provide impetus in support of the NEPAD's objectives. As G8 partners, we will undertake mutually reinforcing actions to help Africa accelerate growth and make lasting gains against poverty ...

We will continue to maintain a constructive dialogue with our African partners in order to achieve effective implementation of our Action Plan and to support the objectives of the NEPAD. We will take the necessary steps to ensure the effective implementation of our Action Plan and will review progress at our next Summit based 
on a final report from our Personal Representatives for Africa.

Patience is obviously running short, and on the Gleneagles G8 website 2005 - under the heading of FAQ - we find the following statement: 'Progress has been made by the G8 and through NEPAD, but we are aware there is still more to be done. We believe it is crucial that the international community gets behind the Africa-led agenda'.

Recognition of the progress is not linked to the achievement of any specific results or the reports of African organisations on the achievement of results, let alone impacts. But the site provides an answer to those who might question the timing of new initiatives before "old" initiatives have been taken on board and had time to mature:

The timing of the Commission's work is intended to seize 2005 as an opportunity to make a difference for Africa. 2005 will see the coincidence of the United Kingdom's chairmanship of both the G8 and, in the second half of the year, the European Union, with Africa high on both agendas.

Reconciling the timing of new programmes, such as that of the Commission for Africa and ongoing capacity development processes, needs urgent attention. Requirements of participation and accountability, of monitoring and reporting that are usually key elements of successive programmes, will hardly receive attention if all actors tacitly accept that they will soon be overridden.

Moreover, to determine time requirements is a difficult task indeed. It takes time to introduce and implement new concepts of good governance into the public sector. But these concepts generally depend on civil society organisations developing, accepting and embracing these concepts. All this in turn depends very much on the inherent dynamics of these organisations to achieve, for example, a measure of accountability in its statutes, in its decision-making procedures and other actions. Only to the extent that these are robust enough to withstand incentives that push towards quick action will they be in a position to claim a minimal degree of transparency and accountability.

An interesting illustration of the function of time for reforms has been provided by the Permanent Secretary in charge of the Tanzanian civil service.
He suggested that one possible explanation of the success of civil service reform in that country that won general praise, is the pursuit of principles and ideas that date back to the Nyerere administration. These principles had been superseded originally by a contradictory practice. They are now bearing fruit as the generation that was most active during the 1970 s has risen to the top. ${ }^{1}$ The gestation period may be shorter in many cases. But the example demonstrates the time horizons and the risks involved in determining the time periods required to expect outcomes in areas that are notoriously difficult to influence, to monitor and measure. Since time is of the essence for highly geared support programmes, there is a need to pursue capacity development in the teeth of adverse timing.

New initiatives funded by additional aid may give short shrift to many achievements that have been introduced in recent years - beginning with gender-sensitive approaches to reforms, passing on to the mainstreaming of anti-corruption mechanisms, ${ }^{2}$ and to supporting human rightsbased approaches of service delivery. Will these considerations that took a long time to lock into the methods and instruments of donors and recipients alike, need to yield as they stand in the way of speedy spending to attain the MDGs?

\section{Opportunities}

'Without progress in governance, all other reforms will have limited impact', the report of the Commission for Africa tells us. This lesson has been repeated over and over again. But the report misses the point - because it assumes that capacity development for governance is a discrete stream of activities, ancillary to and accompanying other reforms. One gets the impression that infrastructure and other investment programmes can be successfully implemented without governance capacity. Or the necessary capacity can be created and managed with the help of added technical assistance projects, as was the habit during the times of structural/sectoral adjustment programmes.

In a different vein, the report states that governance capacity building is essentially a domestic task for recipient governments, in contrast to infrastructure, which is considered a fitting task for donors.

With the help of increased aid, this logic may be reversed. Issues of public sector reform could be addressed on a major scale, and that could help the 
public sector recover from the deficits that have been plaguing it since the time of structural adjustment. Then the public sector was often considered to be unable to perform even minimal functions. Its capacity shrank as austerity ate into the budgets available for public service pay and operations. Downsizing ensured that those who could find jobs abroad or in the private sector went there, if they had not joined donors in the first place. Downsizing also burdened the public sector with heavy future pension obligations. Massively increased aid could be used to make capacity development for governance a central concern of donors.

\section{Capacity: the donor problem}

The argument for making the public sector a target for increased aid becomes apparent by comparing the following two statements. The report of the Commission for Africa puts it traditionally:

Africa's history over the last fifty years has been blighted by two areas of weakness. These have been capacity - the ability to design and deliver policies; and accountability - how well a state answers to its people. Improvements in both are first and foremost the responsibility of African countries and people.

And then it continues: 'But action by rich nations is essential too'.

Compare that with this comment: 'Thus, state building is not an act of simple charity but a smart investment in the United States' own safety and stability' (Eizenstat et al.).

If we take "state building" as the latest euphemism for developing governance capacity, a major increase in aid can help us conceive of the state and its capacity as a major donor problem that needs to be tackled with the highest priority, rather than a constraint on greater donor effectiveness to be left with partner governments. Closing our eyes to the recent history of the civil service, especially in countries with weak institutions, cannot be a recipe for effective capacity creation for reaching the MDGs. While responsibility for governance has of course to remain with the African people, the ways in which governance capacities can be developed need to be given a fresh look by all of those that feel bound by the MDGs. ${ }^{3}$

We look at increased aid not as a new "Marshall Plan for Africa" but rather as a "big push" that allows us to reconsider some current thinking - for example, about the task of "reinventing" the postcolonial state in Africa; in particular for those countries that are usually classified as aid dependent. This is certainly not a game developed countries should be watching from the sidelines - especially since for geopolitical reasons, attention is now focused on states and governance as crucial to the maintenance of world order. A joint endeavour in support of governance may also assist donors in developing a more integrated and eventually coherent view of the numerous and varied arenas necessary to build capacity - taking into account the globalised environment for African governance. ${ }^{4}$

Increased aid can help to put the issue of increased capacities at the centre of development cooperation policies. Making donors understand that capacity creation and management is a crucial problem, and not a constraint on well-intentioned sector activities, would be a great advance.

Ever since it has been introduced as an issue into the development discourse, governance was considered more of a diversion, an add-on to other more substantive reforms. Governance did not promote or realize sector goals directly. What's more, governance principles did not contribute to more capacity. The MDGs are a case in point. Their objectives have been set in isolation. And they are pursued and can be reached in a way neglecting organisational and societal processes and by the same token processes of capacity development. The Millennium Declaration cannot create the intrinsic link between the Millennium Goals and the capacity and principles required to reach them.

Reforming the public sector to maintain or increase capacities appeared to be an obstacle blocking the road to progress in many if not all public goods and services. When structural adjustment was still the flavour of the day and when big lenders realised that they had not really an "adjustment" but a reform issue at hand, they chipped in rather randomly designed programmes to improve the state's ability to deliver public health, education, and economic reform but also balanced budgets, market-led pricing systems, and privatised enterprises. With few exceptions the question of how to manage change by creating the necessary capacity was not put on the agenda. Constraints of institutions that designed and managed policies were not really taken seriously because the policies were delivered ready to be used. 
Today, this perspective has not changed explicitly. New funds should be an opportunity to put into practice some of the lessons that have been learned since the end of the 1990s.

\section{A competitive yet principled public sector}

Milton Friedman said a couple of years ago that his advice to former socialist countries 10 years earlier had been to 'privatise, privatise, privatise.' 'But I was wrong,' he added. 'It turns out that the rule of law is probably more basic than privatisation. (Fukuyama 2004: 36)

To achieve the MDGs, donors will have to understand that a principled and competitive public sector is crucial. Increased capacities and the promotion of good public administration principles have to go hand in hand. And one of the major underlying factors is a public service that is competitive. It needs to be given the resources to operate on equal footing with the private sector. The public sector should not be forced - or tempted - to use other means, notably its link to political power, to mobilise influence and funds.

Increased aid will make a difference by helping to attract and retain well-trained and well-paid personnel to the public sector. Since this exercise will have to go hand in hand with providing services in various sectors, several methods of delivery may serve this purpose.

1. A transitional build-up of parallel capacities with at its centre strategies of capacity reform and deployment:

(a) additional/parallel capacities linked to specific sectors but reinforcing general structures and set up in accordance with rules of general validity - no social fund-type operations that do not report to the government hierarchy

(b) generalised upgrading of existing capacity

(c) making the public sector ethos a central issue.

2. A special programme to revamp public sector human resources:

(d) increasing civil services' status and reputation - a determined effort of staff retention - and, in parallel

(e) redirecting human resources that have been poached by the international private sector $-\mathrm{a}$ reversal of the brain drain (f) improving access to careers from where students are

(g) creating structures that can direct these capacities to the main areas of need - active personnel management.

3. Creating a host of service centres that are able to support additional management tasks of local government or of civil society organisations acting as midwives or as strategic managers, pursuing transparent policies and incentives.

In dealing with these structures, one should be aware of two principles: do not separate policies from implementation and do not centralise policy management. Consider externally created capacity centres as an integral part of the public management landscape of the country within which they operate. Consider them as actors with interests and the resources to pursue them. But make sure that they are bound by and respond to values and principles that are guiding the public sector in its entirety, and which distinguish the sector and its service from others. Or conversely, respond to their demands for systems that ensure their integration into a common framework which might be virtual in the beginning, but which would gain more substance over time.

Management capacity is a scarce resource. Thus, increased aid should provide the means to improve capacity management skills, in a generalised fashion, across the entire public sector. Otherwise we will again create small islands in a sea of incompetence and indifference. Such meagre improvements are neither sustainable nor significant for reaching ambitious goals such as the MDGs.

Advocating parallel structures - the capacity centres described above - is a risky business. The history of these entities driving the social investment funds of the 1990s is full of examples where parallel structures have put in peril weak public sector institutions. In order to counter these evident risks, transfer and exit strategies need to be put in place and monitored. But strategies of this kind have always been part and parcel of capacity development. In this new context, they are essential to guarantee the feasibility of this strategy. 


\section{Notes}

1. Conversation with Joseph A. Rugumyamheto, April 2002.

2. As a reminder of how difficult it is to pursue anti-corruption activities, compare the observations regarding the UK's performance implementing the Anti-Bribery Convention, Financial Times, 19 March 2005.

\section{References}

Eizenstat, S., Weinstein J. and Porter, J., 2005, Foreign Affairs, January/February

Fukuyama, F., 2004, State-Building: Governance and World Order in the 21st Century, Ithaca: Cornell University Press

3. This idea has been suggested to the author by Dele Olowu, adviser to the African Development Bank.

4. For a start it is helpful to consider arenas such as trade, migration, intellectual property protection, investment and financial transactions. 